\title{
Commentary: Targeting the left atrial appendage
}

\author{
Marc Gillinov, MD, Daniel J. P. Burns, MD, MPhil, \\ and Rakesh M. Suri, MD, DPhil
}

Stroke prevention is a primary goal in the management of patients with atrial fibrillation (AF). First-line therapy in this regard consists of systemic anticoagulation with either warfarin or a direct oral anticoagulant. These medications are extremely effective, reducing the stroke risk by $60 \%$ or more in patients with $\mathrm{AF}^{1}{ }^{1}$ However, this comes with the tradeoff of increased risk of bleeding. In addition, compliance with oral anticoagulants is variable. These well-recognized limitations have fueled the development of mechanical means to occlude the left atrial appendage (LAA) and thereby reduce stroke risk in patients with AF. Randomized controlled trials in both the surgical and interventional literature confirm that LAA management does, indeed, reduce the risk of stroke and other thromboembolic events in patients with $\mathrm{AF}^{2,3}$

When cardiac surgeons encounter patients with $\mathrm{AF}$, it is generally in the setting of concomitant structural heart disease (eg, mitral regurgitation, aortic stenosis, coronary artery disease). At the time of surgery, these patients are best served by a Cox-maze IV procedure, which includes management of the LAA. With current technologies, this addition to the operation takes less than 30 minutes and does not increase surgical risk.

In contrast to concomitant $\mathrm{AF}$ management, sole therapy for $\mathrm{AF}$ has not become a common surgical procedure. The relative successes of catheter ablation and the percutaneous

\footnotetext{
From the Department of Thoracic and Cardiovascular Surgery, Cleveland Clinic, Cleveland, Ohio.

Disclosures: Dr Gillinov is a consultant to Edwards Lifesciences, Medtronic, Abbott, CryoLife, AtriCure, and ClearFlow and Dr Burns to Medtronic. Dr Suri reported no conflicts of interest.

The Journal policy requires editors and reviewers to disclose conflicts of interest and to decline handling or reviewing manuscripts for which they may have a conflict of interest. The editors and reviewers of this article have no conflicts of interest.

Received for publication Aug 2, 2021; revisions received Aug 2, 2021; accepted for publication Aug 3, 2021; available ahead of print Aug 8, 2021.

Address for reprints: Marc Gillinov, MD, Department of Thoracic and Cardiovascular Surgery, Cleveland Clinic, 9500 Euclid Ave/Desk J4-1, Cleveland, OH 44195 (E-mail: gillinom@ccf.org).

JTCVS Techniques 2021;9:69-70

2666-2507

Copyright (c) 2021 The Author(s). Published by Elsevier Inc. on behalf of The American Association for Thoracic Surgery. This is an open access article under the CC BY-NC-ND license (http://creativecommons.org/licenses/by-nc-nd/4.0/)

https://doi.org/10.1016/j.xjtc.2021.08.005
}

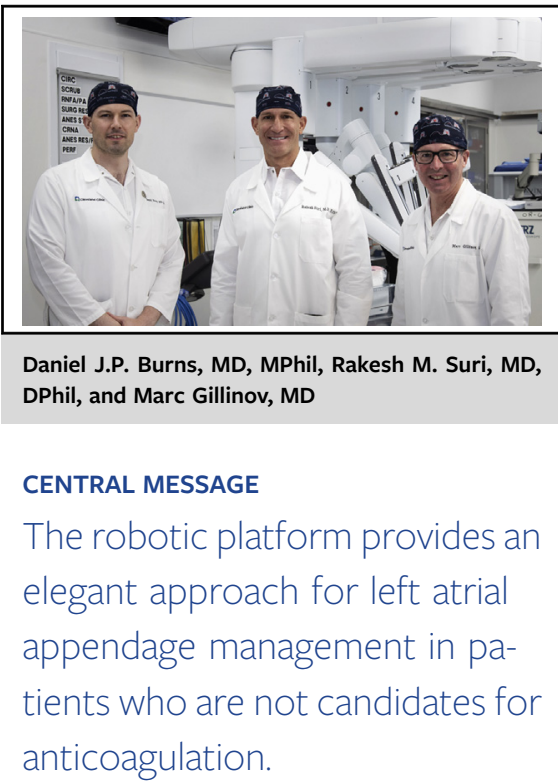

Watchman device, combined with the perceived invasiveness of surgery, have combined to limit the surgeon's role in this arena. However, many patients are not candidates for percutaneous strategies to manage AF; to serve these patients, surgeons must offer a safe and minimally invasive surgical approach.

Antaki and colleagues ${ }^{4}$ make an important contribution with their demonstration that robotically assisted LAA exclusion offers a safe, effective, and minimally invasive option for patients with AF. The majority of patients in their series could not tolerate oral anticoagulation and were therefore unsuitable candidates for percutaneous LAA closure (as Watchman implantation is generally followed by a period of oral anticoagulation). Among their 42 patients, they had $100 \%$ procedural success and no intraoperative complications.

With these results, robotic LAA management offers an attractive option for patients who cannot take oral anticoagulants. Excellent visualization with the surgical robot may provide an advantage over standard thoracoscopic techniques. However, as the authors note, robotic surgery entails a substantial learning curve. Surgeons with robotic experience can employ the technique described by Antaki and colleagues and achieve clinical success. In contrast, those who do not already use the surgical robot may wish to pursue a thoracoscopic approach to LAA management. With the high and increasing prevalence of AF, a surgical group that offers safe, effective, and minimally invasive LAA management will surely have patients to serve. 


\section{References}

1. Ruff CT, Giugliano RP, Braunwald E, Hoffman EB, Deenadayalu N, Ezekowitz MD, et al. Comparison of the efficacy and safety of new oral anticoagulants with warfarin in patients with atrial fibrillation: a meta-analysis of randomized trials. Lancet. 2014;383:955-62.

2. Whitlock RP, Belley-Cote EP, Healey JS, Healey JS, Brady K, Sharma M, et al. Left atrial appendage occlusion during cardiac surgery to prevent stroke. $N$ Engl J Med. 2021;384:2081-91.
3. Holmes DR, Kar S, Price MJ, Whisenant B, Sievert H, Doshi SK, et al. Prospective randomized evaluation of the Watchman left atrial appendage closure device in patients with atrial fibrillation vs. long term warfarin therapy: the PREVAIL trial. J Am Coll Cardiol. 2014;64:1-12.

4. Antaki T, Michaelman J, McGroarty J. Robotics-assisted epicardial left atrial appendage clip exclusion. J Thorac Cardiovasc Surg Tech. 2021;9: 59-68. 